\title{
Examining Job Accessibility of the Urban Poor by Urban Metro and Bus: A Case Study of Beijing
}

\author{
Chun Zhang ${ }^{1} \cdot$ Joyce Man $^{2,3}$
}

Received: 21 September 2015/Revised: 17 October 2015/Accepted: 24 October 2015/Published online: 30 November 2015

(C) The Author(s) 2015. This article is published with open access at Springerlink.com

\begin{abstract}
Using data from Beijing, this paper evaluates job accessibility for people living in affordable housing to job centers by public transit, including urban metro and bus. By comparing the middle and low-income group who mainly use public transit and higher income group who mainly travel by car, results show an accessibility gap for different modes of transportation as travel by public transit takes nearly double the amount of time as travel by car. While commuting time is closely linked to the location of the provided affordable housing, it is also dependent on the quality of local public transit service. Areas with substantial travel time differences between public transit and car travel reveal the weaknesses of public transit provision. Furthermore, average commuting time by both public transit and car from areas of affordable housing built after 2004 is much longer than that from previously built areas implying that low-income groups are being driven to more disadvantaged locations with time changes. In contrast to the classical job-housing mismatch hypothesis in U.S. cities, the mismatch model in Chinese cities is that while major job opportunities are still concentrated in the central city, affordable housing residents who rely on urban metro and bus are being moved further afield into distant suburban areas. The paper will provide the
\end{abstract}

Chun Zhang

zhangc@bjtu.edu.cn

1 School of Architecture and Design, Beijing Jiaotong University, Beijing, China

2 School of Public and Environmental Affairs, Indiana University Bloomington, Bloomington, USA

3 Lincoln Institute Center for Urban Development and Land Policy, Beijing, China

Editor: Prof. Haishan Xia implication for affordable housing and transportation planning in Chinese cities in the future. Improving job accessibility by further establishment of urban metro system for this demographic will promote the urban economy and provide social welfare for the disadvantaged.

Keywords Accessibility · Job-housing mismatch · Urban metro $\cdot$ Affordable housing $\cdot$ Beijing

\section{Introduction}

Job accessibility has been a hot research topic for urban planning professions and policy makers for a long time, especially with the rise of the New Urbanism movement and smart growth policy [27, 31]. It is believed that better job accessibility will not only calm down traffic [15] and reduce greenhouse gas emissions [1], but also improve local employment and social inequality for the disadvantaged groups [4, 19]. In this sense, better job accessibility is desired by both urban planners and policy makers.

However, the detachment between employment and housing has been on the rise across the globe, though especially in U.S. cities in the past few decades $[8,9,10,36]$. This detachment trend is simultaneous with large-scale urbanization and urban sprawl at the end of twentieth century. Both spatial and non-spatial factors play their part in determining job accessibility. For example, empirical study supports that land-use pattern decides about one-third of the driving distance between the workplace, home, and other destinations [7]. In this sense, the balance of land mix use between job and housing will reduce distance commuting and increase job accessibility [15]. Non-spatial factors also play an important role, for example, discriminatory housing policy toward the Blacks in the neighborhoods in certain American cities [14, 
22, 29]. Because of racial, economic, or even linguistic factors, African-American residents of the inner city are unable to find credible jobs in the city core, but have to commute a long way to labor-intensive jobs located in far suburban areas [24, pp. 95-131;26].

Similarly to the U.S. cities, the job-housing balance in the cities of developing countries [19, 29, 36], such as China, has also been decreasing in this era of rapid urban expansion. This paper selected Beijing as a case study, for it shows a unique job accessibility pattern carrying strong post-socialism characters as the national capital and the second biggest city [34].

In recent years since the 1990s, large amounts of affordable housing units have been developed in the urban fringe far from the city center [13]. At the same time, however, the majority of job opportunities are still concentrated in the urban center [40]. And although the level of car ownership keeps increasing, it is still not high, which means that the urban poor are still mostly dependent on public transit [38].

This paper selects Beijing as a case study and evaluates the accessibility of jobs for the urban poor who live in affordable housing by calculating the average public transit time from their homes to commercial and industrial job centers. This paper also compares the accessibility of affordable housing projects from before and after 2004 in order to show if the average public transit time has increased or decreased in the wake of the comprehensive plan of 2004.

Due to the limited levels of car ownership in Chinese cities, this paper implies that the calculated job accessibility of the urban poor holds implications not only for urban employment but also for the level of social inequality for disadvantaged groups. Evaluating the accessibility of affordable housing projects will also hopefully lead urban planners and policy makers to reflect on the selection on current affordable housing project sites.

The following parts of this paper will be structured as follows: The second part will review accumulated research on the definition and measurement of accessibility, the benefit of improving accessibility, and related empirical studies in Chinese cities. The third part will give a brief introduction to the background and data of the Beijing case study. The fourth part will explore the spatial distribution of jobs across city, job accessibility across different travel modes, different locations, and in different time periods before and after 2004. The last part will give a conclusion regarding job accessibility of the urban poor in Beijing and its unique features in comparison to that of U.S. cities.

\section{Literature Review}

There are many ways to define and measure accessibility [7], and this paper selects the traditional and simple definition and measurement based on gravity model and network model. Then, this paper reviews the literature on the benefit of improving job accessibility and increasing job-housing balance, and also on the accessibility-related domestic studies on Chinese cities.

\subsection{Accessibility and Measurement}

Accessibility can be defined as the ability and ease to move from one place to access urban facilities in another place and overcome friction such as distance and travel cost [17]. This concept was first brought into the urban planning field in 1959 to measure the potential of interaction [18]. Different from the original idea in the transportation field, the concept of job accessibility in the urban planning field places more emphasis on the relationship between accessibility and the urban land-use pattern [33]. This concept continues to draw attention from both scholars and decision makers, who regard it as an important indicator of good urban planning.

The traditional measurement of accessibility is the gravity model, which is brought up based on distance decreasing rules in geography. The model argues that potential gravity exists among the urban land. In order to access from one place to another driven by this potential, the traveler needs to overcome some friction [7]. Then, accessibility can be measured by aggregate relation to these places in terms of distance, time, or cost. The weight of each place can also be calculated in this way. A longer distance, time, or higher cost indicates that people have less opportunity to work in this area.

Specifically, the simple expression of gravity model is

$A_{i}=\sum_{j} E_{j} f\left(C_{i j}\right)$,

where $A_{j}$ is the accessibility score for people living in zone $i, E_{j}$ is the number of employment opportunities in zone $j, f$ $\left(C_{i j}\right)$ is the impedance function associated with the cost of travel, and $C$ for travel between zone $i$ and zone $j$, For a metropolitan region with $\mathrm{Z}$ zones, $i, j=1,2, \ldots, N$.

The gravity model successfully explains how individuals choose which job centers to work at. However, accessibility in real life highly depends on the transportation network rather than just the spatial distance itself [17]. Thus, the introduction of the real transportation network is an improvement on the original gravity model.

The rules of network analysis come partly from graph theory, focusing on the connectivity among nodes. The simplest network can be depicted as a line between two nodes, A and B and they generate two links: A-B and B-A. When adding more nodes to the network, the links among all the nodes should be calculated based on Law of the Network as 
$S=N(N-1)$,

where $S$ is the network size (number of links) and $N$ is the number of nodes.

Then, the accessibility can be measured using impendence in a real road or public transit network. By introducing the network analysis, in Eq. (1), the equation will be improved from geographic distance to real travel distance, time, or cost based on the transportation network.

\subsection{The Benefit of Better Job Accessibility}

Accumulative research shows that there are many environmental and social benefits of improving job accessibility. New urbanism advocates argue that by improving the job accessibility, not only traffic but also energy consumption and urban sprawl will all be reduced [15, 31]. In addition, studies show that it will relieve traffic jam [12] and cut down the time on road [36]. For example, a case study in San Francisco found that if job opportunities increase by $10 \%$, the commuter traffic will reduced by $3.29 \%$ [10].

Recently, better job accessibility proved to have extra environmental and economical benefits. By reducing traffic, it will help to maintain better air quality $[1,7,15]$. Besides by reducing vehicular commuting time, public health will also be improved [36]. Furthermore, the average cost of commuting will be cut down due to reduced gas consumption.

\subsection{Job Accessibility Study in Chinese Cities}

In the traditional socialist cities, job accessibility was never a problem such as in big, modern Chinese cities. According to the planning system of the planned economy era, employment and housing used to be perfectly balanced within the Work Unit compound [11]. Living and working within the same compound wall is depicted vividly as a "spatial bond" [34]; thus, the job accessibility used to be pretty high in the planned economy era. The character of such a job-housing relationship led to minimal domestic research on the issue of job accessibility until the 1990s.

With the acceleration of economic reform in 1980s, the traditional Work Unit began to collapse and the job-housing relationship began to fundamentally change [11]. The termination of state-provided housing in 1998, a milestone in Housing Reform, triggered the process of large-scale residential relocation to suburban areas [20]. Nonetheless, the economic heart of the city still remained in the city center, inducing a change of the job-housing relationship and decrease in job accessibility.

For example, Liu and Wang found that job-housing spatial mismatch began to form and impacted the everyday commuting behavior based on the questionnaire in Beijing, and job accessibility began to decrease [41]. Zhao and Lu argue that the traditional job-housing relationship still has an institutional legacy on job accessibility in the current transition period of Beijing [38]. In a case study of a southern city, Guangzhou, it was found that with the disappearance of Work Unit and the commercialization of housing, the commuting distance became longer, and the commuting spatial structure was changed [25]. Similarly, Zhou noted the excess commuting phenomena based on the TAZ analysis in Xi' an as a western city in China [43]. Based on the cases above, job accessibility turned worse since the 1990s in most of the Chinese cities with the trend of quick urbanization and job-housing relation changes.

\section{Method and Data}

\subsection{Study Area}

Beijing is the national capital in the north of China and has a population of over 17 million [3]. While China has been successful in reducing poverty in recent decades, the urban poor in Chinese cities still faces the usual difficulties that come with limited income. In reality, the gap between the urban rich and the urban poor is not only based on salary, but also on the urban resources supported or provided by the municipal government. These urban resources include transportation facilities, education facilities, hospitals et al., and this paper will focus on the job accessibility of the urban poor. It is worthy to note that the way people travel has evolved tremendously from planned economy period to the transition period.

Pre-reform Beijing was defined by the development of self-contained work units, or danwei. People work and live within their danwei, and all activity (shopping, recreation and education) occurs within the boundaries of these danwei [37]. However, with the collapse of the traditional work unit, the relationship between occupation and housing has fundamentally changed. On one hand, people began to find jobs outside of the walls of their respective danweis, releasing the spatial bond. On the other hand, the privatization of the housing market and inner city redevelopment has driven people into large housing projects in the outer edges of the urban fringe, while the job centers remain in the center of the city. This has resulted in the low job accessibility and job-housing spatial mismatch apparent in post-reform Chinese cities, the result of the detaching of jobs and housing.

Along with the increased work-home commute, private car ownership in Beijing has also increased dramatically. 
By 2008, there were approximately 3.25 million cars in Beijing, and this number has been rising steadily by $15 \%$ each year [39]. While huge amounts of investment are supporting the rapid growth of the road network, another half of all transportation investment goes toward building public transit systems including bus, mass rapid transit, and rail. By 2010, there were a total of 678 bus lines and a total length of 174.2 thousand $\mathrm{km}$ of road covered by the bus system in Beijing. At the same time, the urban metro system grew at a dramatic speed in the first decade of twenty-first century. Based upon subway Line 1 and Line 2 , which were built in 1969, the subway system has expanded to a sprawling 14 lines and a total length of $323 \mathrm{~km}$ by 2010 . Despite the investment in the improvement of public transit, a great amount of maintenance fees goes to subsidize the bus and subway ticket prices, making Beijing one of the cheapest public transit cities in China.

Despite the substantial investments on both urban metro and bus, the spatial mismatch between housing and employment still plagues the urban poor. However, the occurrence of spatial mismatch is different from the U.S. cities: (1) the affordable housing projects are mostly located in the urban fridge [13] and some of these projects are far away from public transit. (2) Main job centers are still concentrated in the central city. (3) The rate of car ownership is still low and commuters rely more on public transportation [39]. In consideration of the above characteristics, the job accessibility of low income can be measured as the commuting time that the urban poor living in the urban fridge have access to central city job opportunities by public transit.

\subsection{Data Source and Method}

This paper has selected the Beijing urban area within the 6th ring roads as the study area including the administrative districts of Dongcheng, Xicheng, Chaoyang, Haidian, Fengtai, and Shijingshan (Fig. 1). The land, job, and transportation data were collected between 2001 and 2004, while the affordable housing data were collected from 1999 to 2010 [44].

First, the housing data come from the affordable housing projects, which partly represent where the urban poor lives. Second, this paper combines the land-use map in 2004 and economic data in 2001 to identify the job centers. Specifically, it extracts the location of commercial land as the potential job centers. By overlapping the job density within the zip zones based on the economic basic unit survey conducted in 2001, the intensity of the concentration of jobs at each center can be calculated. Third, the transportation data between housing and job come from the public transit network and road network map compiled in 2004, representing those who travel by public transit and private car, respectively. Based on the housing, employment, and transportation network data, the OD matrix has been generated to measure the network distance or travel time between job and housing. Then, the job accessibility of the poor living in affordable housing is measured as the average single-way commuting time to all the various potential job centers (Fig. 2).

The method outlined above is based on the following hypotheses: (1) The residents of the affordable housing units are identified as low income. ${ }^{1}$ (2) Low-income groups tend to rely on public transit, while those in higher income groups tend to drive their own cars. (3) The commuting time by public transit is calculated by Bus time $=$ walking to the nearest stop $(\mathrm{A})+$ waiting time $(\mathrm{B})+$ travel time on public transit $(C)+$ walking to the destination (D); With commuting time by car as Car time = driving time (E) + parking time (F). For simplicity's sake, this paper supposes A, B, D, and F to be 5 min. (4) That the average speed for a public bus is $16.6 \mathrm{~km} / \mathrm{h}$ [42], while the average speed for a private car is $40 \mathrm{~km} / \mathrm{h}$ (BJTRC [2].

\section{Discussion and Results}

Based on the data and hypothesis above, most of the employment opportunities are still concentrated in the city center. Here, job accessibility can be measured by the average commuting time to all the potential job opportunities. By comparing the commuting time between using public transit and driving, the job accessibility gap between low-income group and higher income group can be observed. Furthermore, the comparison of the commuting times calculated with a starting point of affordable housing locations built before and after 2004 will show the change in the job accessibility of the urban poor.

\subsection{Distribution of Employment Opportunities}

According to the employment data of 2001, despite the fact that most of the affordable housing projects are located in the suburban area outside of the third ring road, most of the employment opportunities are highly concentrated in the city center. It especially shows that the job density is much higher in the inner city than the suburban area and also much higher in the northern than in the southern part of city (Fig. 3).

Specifically, three main job-rich areas are identified as their job density is over 300 jobs per hectare: Guomao in the east, Jinrongjie in the west, and Anzhen in the northeast. There is nearly no affordable housing located within

\footnotetext{
${ }^{1}$ Although this statement is debatable, it is generally believed that the affordable housing residents are at least middle and low income due to the qualification requirements of affordable housing applications.
} 
Fig. 1 Case study of Beijing with affordable housing projects and commercial job centers

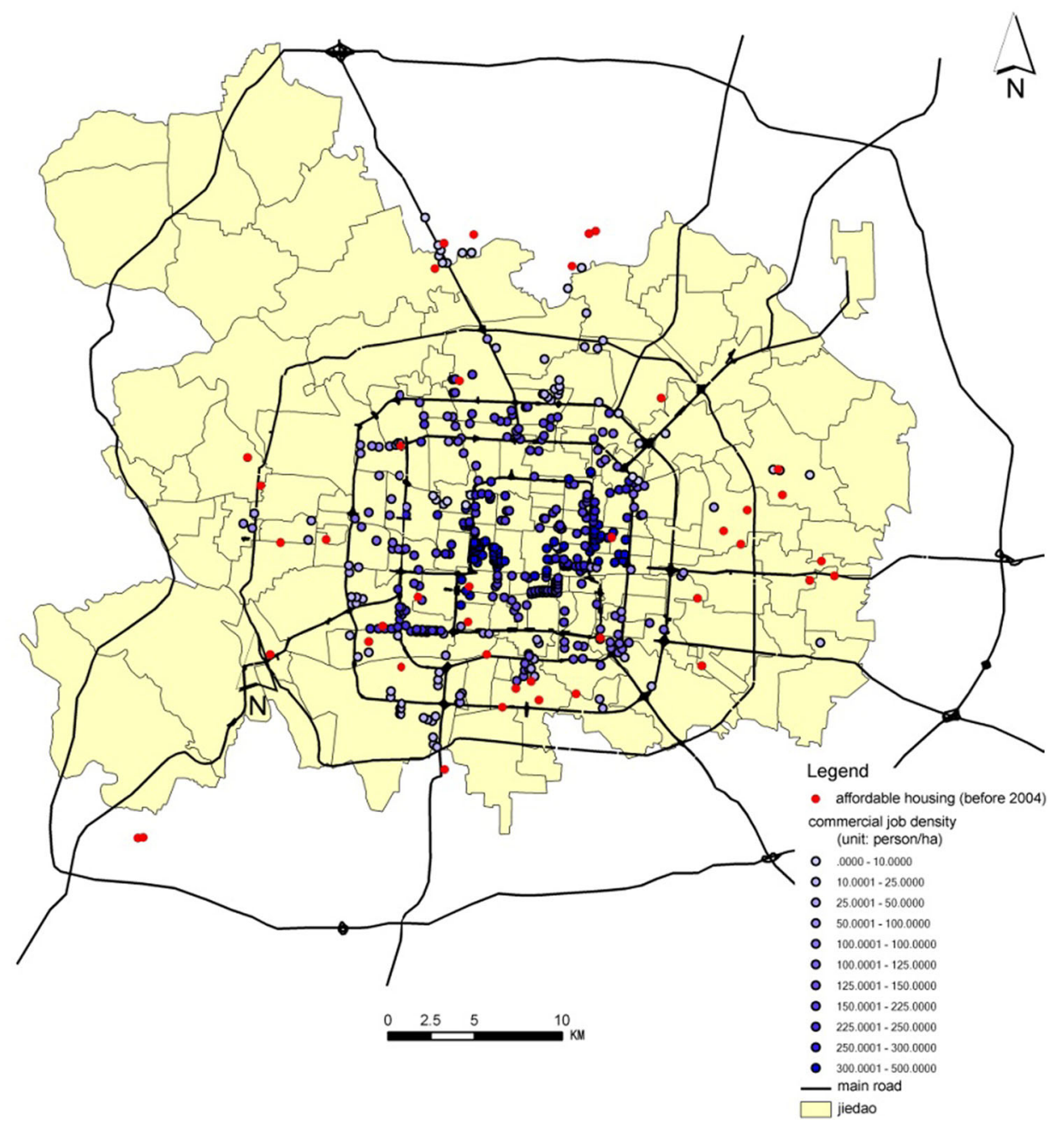

the job-rich areas. On the contrary, in the suburban area zip code zones, where the affordable housing is located, the job density is usually as low as $20-50$ jobs per hectare.

Basically, there were no sub-centers located in the suburban area as of 2001, a fact which clearly reveals jobhousing mismatch problem for affordable housing residents. In this way, the main commuting direction for most affordable residents is toward the city center. As discussed in the accumulated literature, the highly concentrated distribution of employment opportunity shows the strong character of the post-socialist city.

\subsection{Travel Mode Difference of Job Accessibility}

According to the reach method and data preparation, the measurement of accessibility can be simplified to create the OD matrix from the all the affordable housing projects to all the potential commercial job centers.
First, the service area analysis shows the accessible range difference between who travel by bus and by car. Taking an affordable housing development, Fengtishidai in Fengtai district, as an example, $34.9 \mathrm{~km}^{2}$ of commuting area can be reached within $30 \mathrm{~min}$ of travel by public transit (Fig. 4, left), while as large as $454.8 \mathrm{~km}^{2}$ can be reached by car (Fig. 4, right). In this case, the commuting area is much larger for car drivers than for public transit users.

Second, based on the service area analysis, the accessibility for each affordable housing project can be measured by using the average commuting time to all potential commercial job opportunities. The OD matrix of commuting time based on the bus network is generated using the origins of 73 affordable housing areas to the destinations of $418 \mathrm{com}$ mercial job centers. For example, the highlighted case of affordable housing area Wangjingxincheng shows that residents need an average of $56.5 \mathrm{~min}$ to travel to all the commercial job centers (Fig. 5, left). This average 


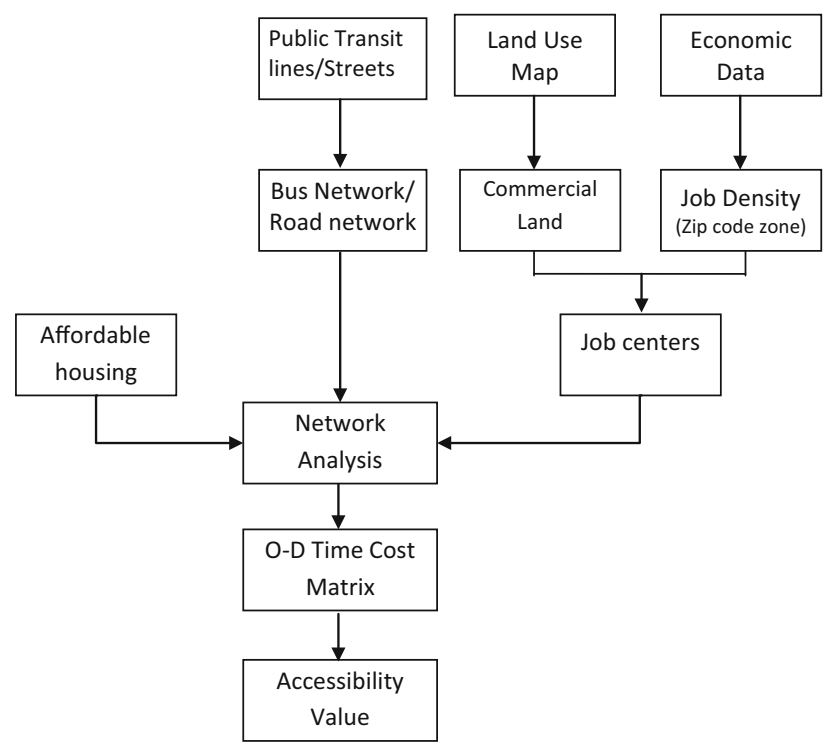

Fig. 2 Network analysis approached to job accessibility commuting time can be an index to measure job accessibility. Generally speaking, it takes $59.4 \mathrm{~min}$ on average for the affordable housing residents to travel to commercial job centers, which is higher than the one-way commuting time for all the residents in Beijing [41].

Third, a similar OD matrix based on the road network from the same origins and destinations is used to measure the job accessibility by car. Again, using the affordable housing area of Wangjingxincheng as an example, the average commuting time by private car is only $26.7 \mathrm{~min}$ which is significantly shorter than the average travel time by public transit. For car users, the average commuting time from all affordable housing sites to commercial job centers as a whole is only 28.9 min; nearly one half of the average commuting time by public transits (Fig. 5, right). This conclusion has similar results to the empirical studies conducted in the U.S. cities, in which different accessibility levels among different income groups do exist [16].
Fig. 3 The commercial employment density of Beijing in 2001

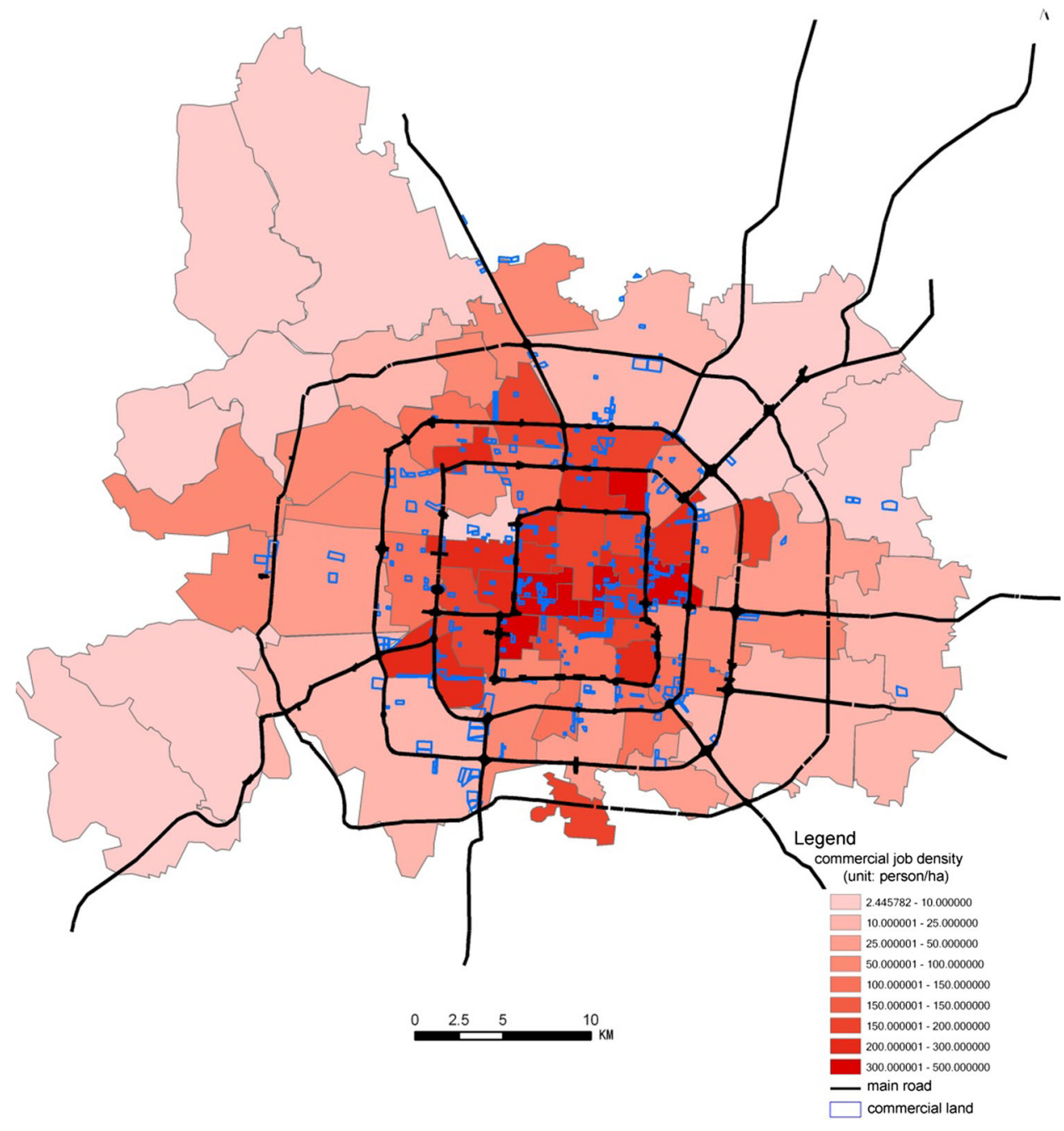



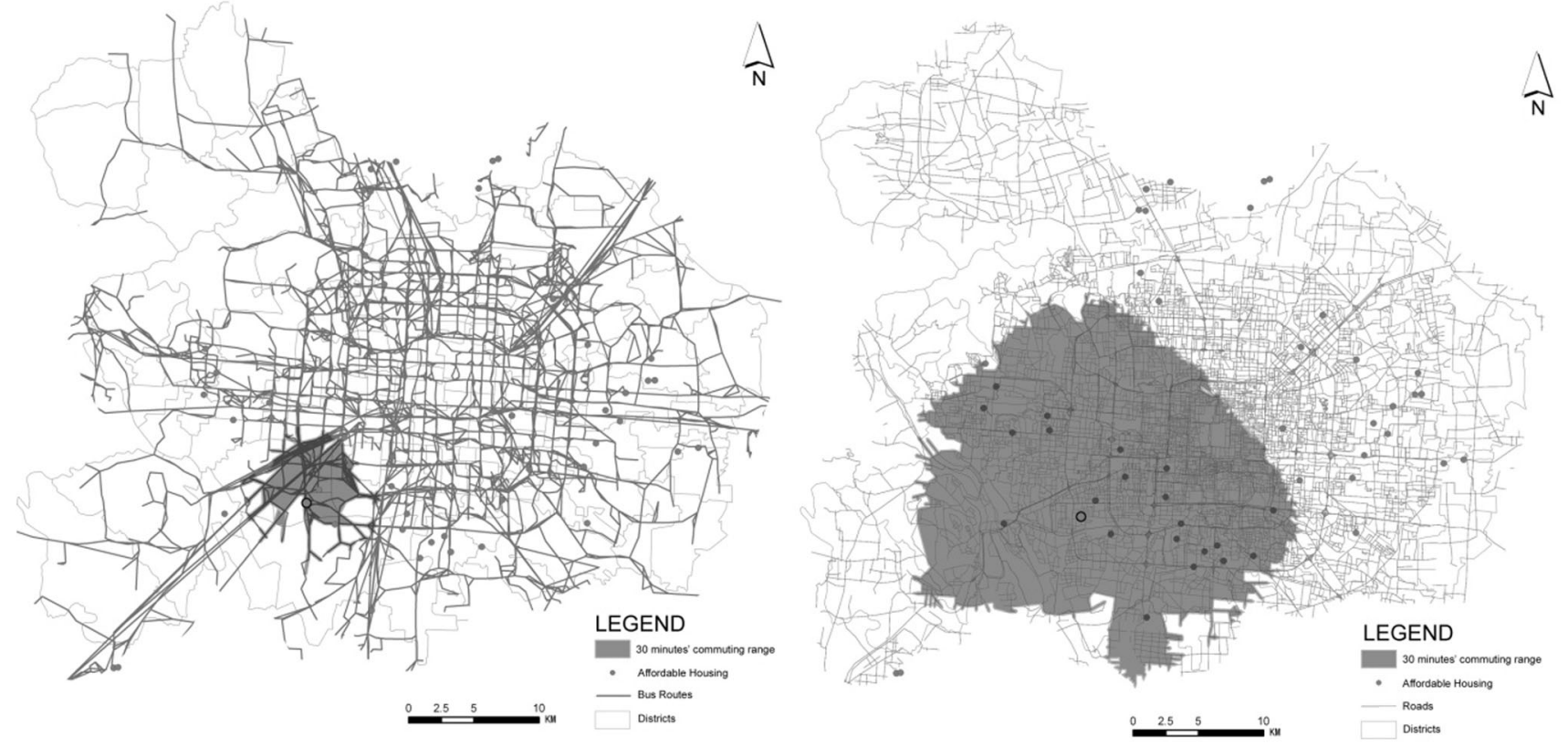

Fig. 4 The accessible commuting area within 30 min by bus (left) and car (right)
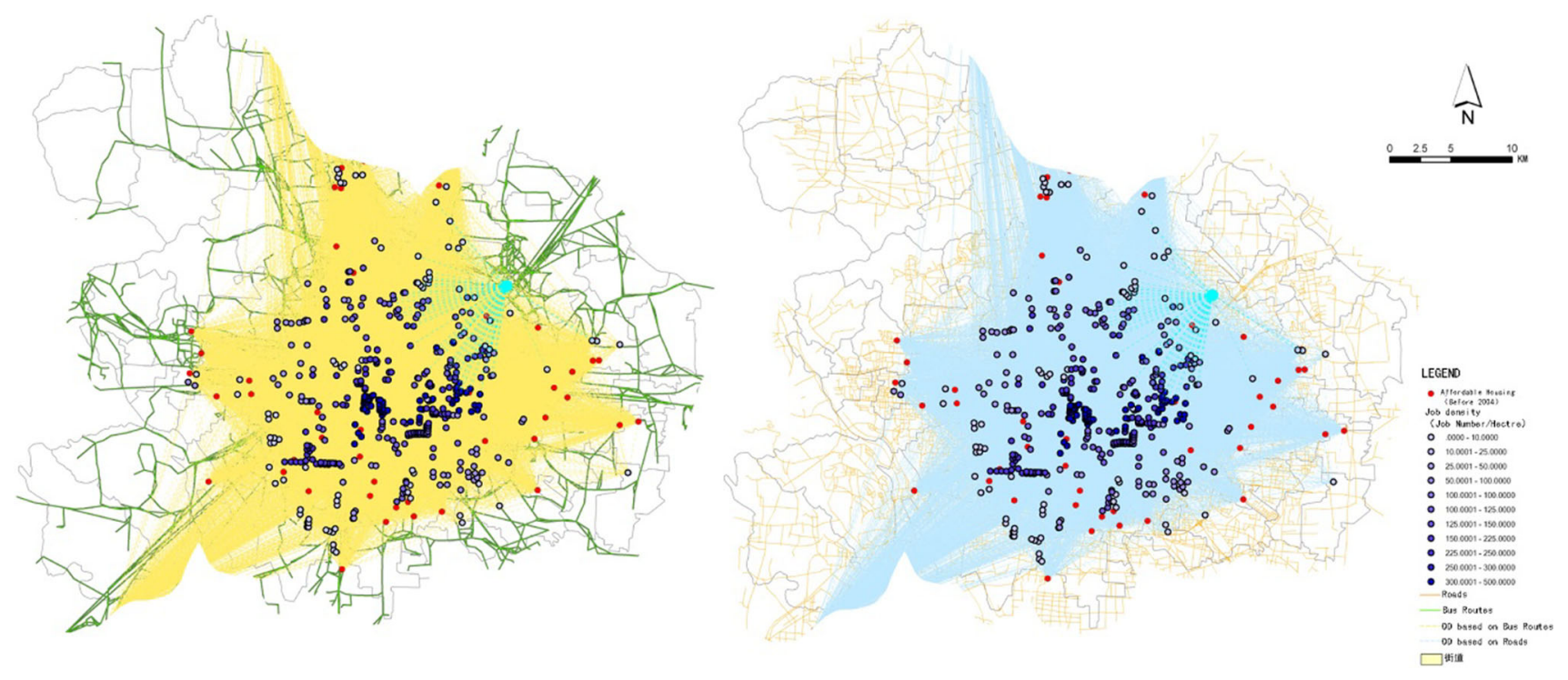

Fig. 5 OD matrix of commuting time based on bus network (left) and road network (right)

\subsection{Spatial Difference of Job Accessibility}

As discussed above, the commuting time using different travel methods reveals the difference of accessibility between different income groups. On average, traveling by public transit takes nearly double the amount of time than traveling by car. As Fig. 6 on the left shows, the average commute by bus is concentrated in the range of 46-60 $\mathrm{min}$, while the average commuting time by car is concentrated in the range of 21-30 min. However, in addition to varying commuting time by different travel methods, the spatial difference of accessibility is also an important issue for the urban low-income groups.

The spatial difference of accessibility is large where the commuting time gap between public transit and car is large. This difference reveals an insufficient supply of public transit services where traveling by bus needs much longer than travel by car (Fig. 6, right). For example, some of the considered cases of affordable housing projects closely follow this model. The affordable housing projects of Huilongguan in the north, Chaoyang New Town and Dingfu Garden in the northeast, and Tiancunluobei in the 

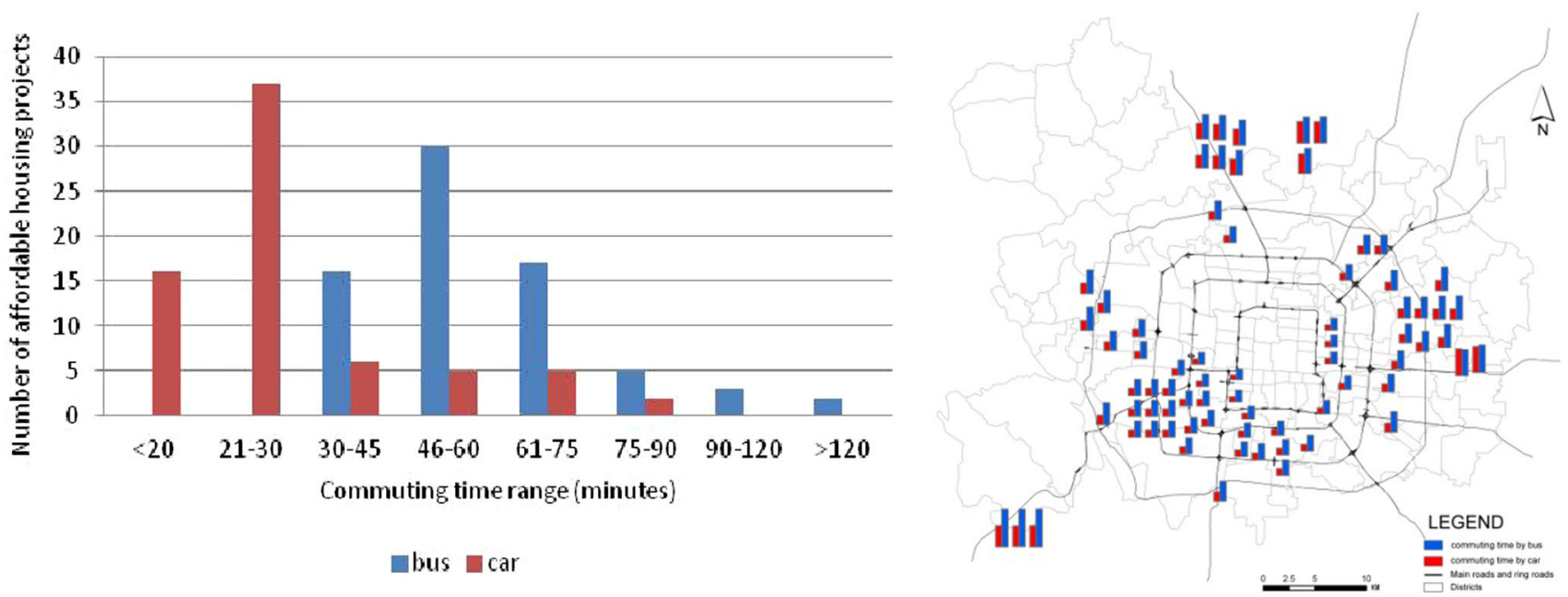

Fig. 6 Commuting time gap between bus and car

west will all need more public transit investment to improve local job accessibility in the future.

From the spatial distribution aspect, the job accessibility of affordable housing is influenced by both the distance to city center and local public transit services. With an increase in distance to city center, both average commuting time by public transit and car are not directly increased, which alludes to the interaction of other local factors (Fig. 7). These results are similar to those concluded on Western cities. Outside of geographical distance, local factors such as land use and public facilities might also influence accessibility [17]. For example, although Huanghuixiaoqu and Jiandongyuan in Dongzhou district are far from the city center, the commuting time gap between bus and car is not large due to the convenient and efficient BTR line and the proximity to subway Line 8 .

The discussion above suggests that the limited job accessibility for some affordable housing residents might not be solely due to the location factor, but also the lack of local public transit facilities. That suggests that low-income groups might be driven to disadvantaged places without convenient public transit facility, especially for the area without urban metro or BRT connection. In American cities such as Los Angeles and Detroit, it has been observed that areas where low-income groups concentrate and have a lack of adequate bus services are prone to experience lowemployment decay [23].

\subsection{Time Changes for Job Accessibility}

Previous sections discussed the job accessibility of all affordable housing sites built between 1999 and 2010 to commercial job centers in 2001, this part will compare the job accessibility for the sites of affordable housing projects before and after 2004.
Generally speaking, a longer commuting time regardless of the transportation method is needed for residents living in affordable housing areas built after 2004 compared to those living in areas built before 2004. If traveling by public transit, the average commuting time increases from $56.5 \mathrm{~min}$ before 2004 to $74.7 \mathrm{~min}$ after 2004. If traveling by car, the average commuting time increases from $28.9 \mathrm{~min}$ before 2004 to $42.8 \mathrm{~min}$ after 2004 (Fig. 8).

The average commuting time needed by residents who travel by public transit shifts to right, red bar from the left, blue bar (Fig. 8, upper right). Before 2004, the average commuting time was concentrated between 46 and $60 \mathrm{~min}$. With the average commuting time's rightward shift, the commute to work for those living in affordable housing has increased with time into the range from 75 to $90 \mathrm{~min}$. This implies that more than a half of affordable housing residents need to travel over 90 min for a one-way commute.

Similarly, the average commuting time by car also shifts rightward (Fig. 8, right down). Compared to bus travel time, commuting time by car is spread out over a greater time range. The amount of time for those living in affordable housing projects to go to work obviously increased, especially for those who need to drive 31-40, $41-50$, and above $60 \mathrm{~min}$.

Again similar to those affordable housing areas built before 2004, the commuting time by both public transit and car from affordable housing areas built after 2004 does not directly increase as the distance from the city center increases, but is rather more turbulency. For example, the relationship between commuting time and the distance to the city center is more irregular after 2004 than before. As for public transit in locations where it is insufficiently supplied, commuting time by bus will obviously require a longer time than commuting time from other affordable housing areas with a similar distance to the city center 


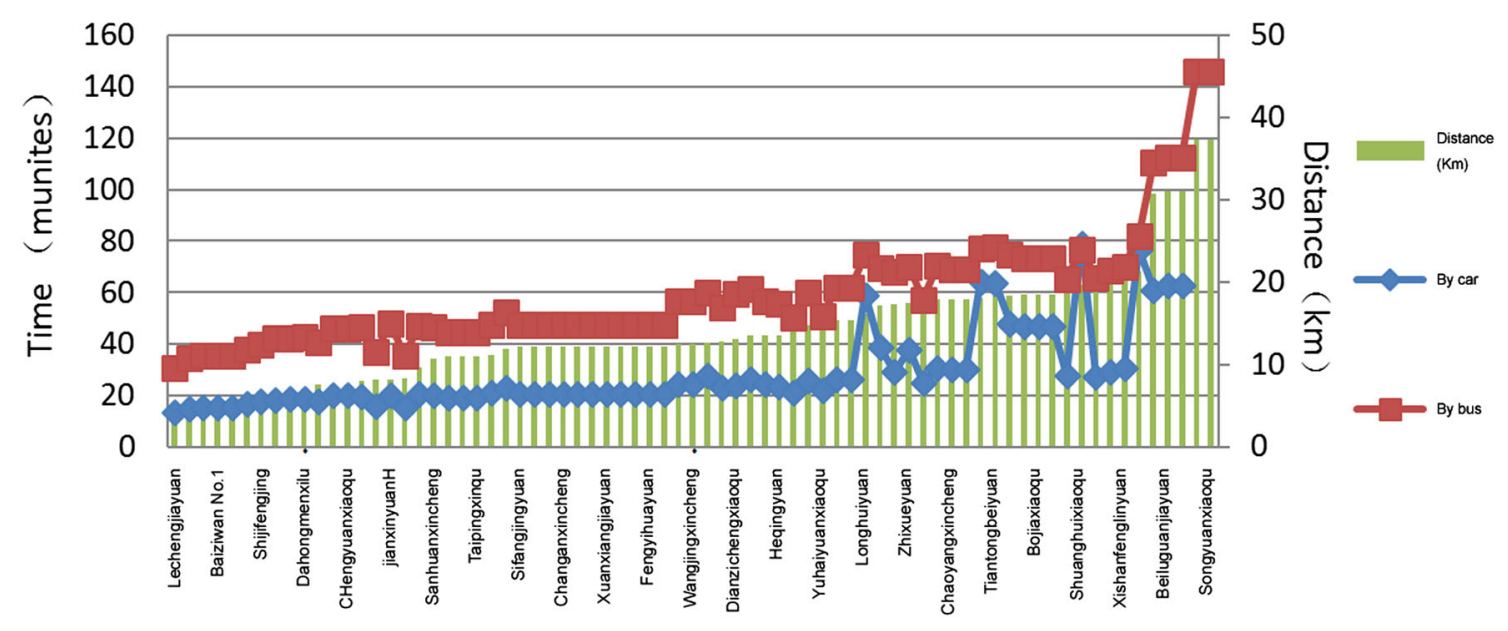

Fig. 7 Distance to city center and commuting time by bus and car for affordable housing (pre 2004)
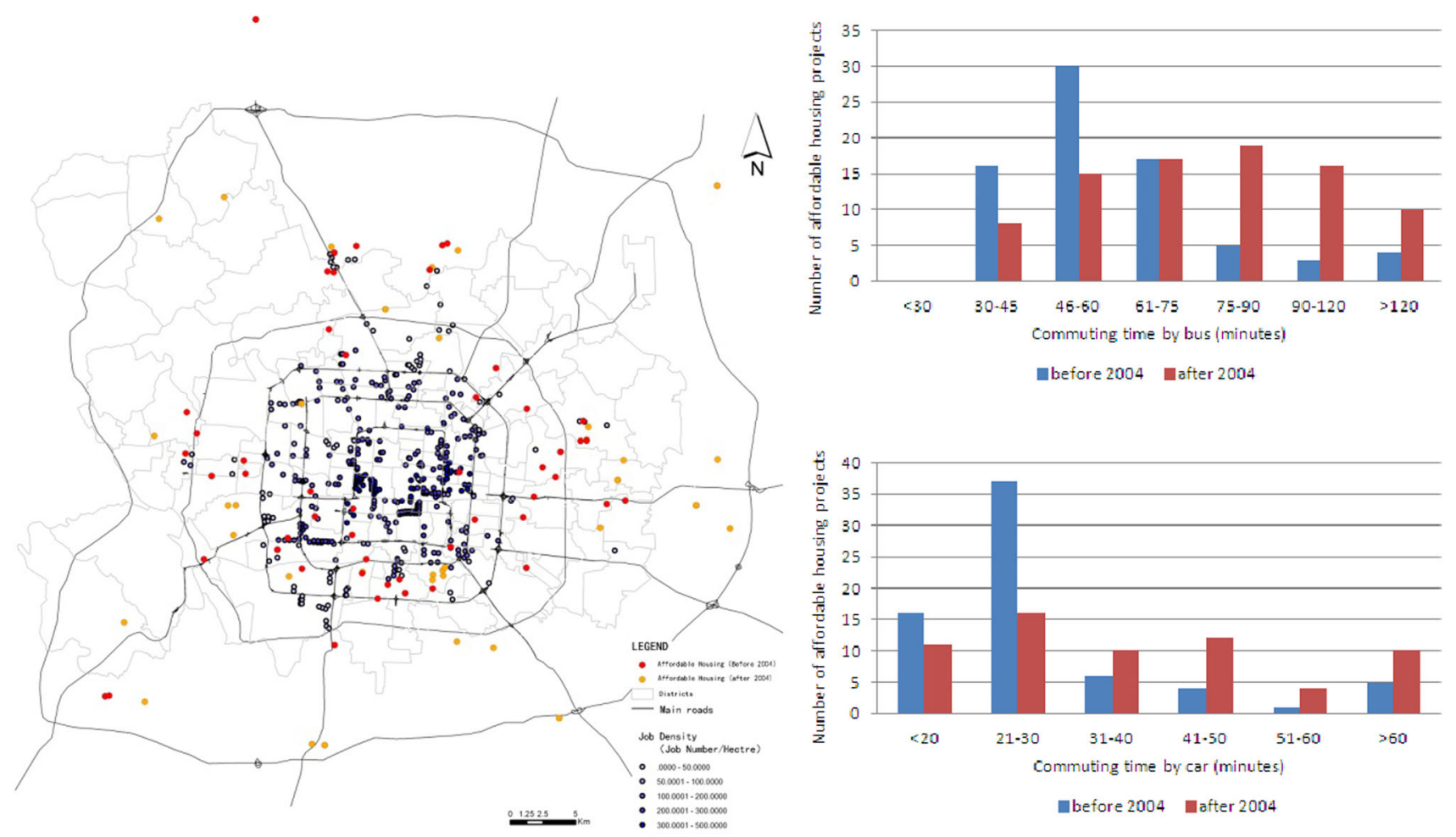

Fig. 8 Commuting time changes for affordable housing before and after 2004

(Fig. 9), such as the affordable housing projects near Chaoyang New Town in the northeast and Tiantongyuan in the north.

In conclusion, from aspect of job accessibility, the affordable housing areas built after 2004 are in worse locations than those built before 2004, which has forced the urban poor into more disadvantaged locations. That mostly because the selection of affordable housing sites moves to more remoting place far away from the city center after 2004 in Beijing. Actually in most Chinese cities, although there is no housing discrimination policy toward the minority low-income groups $[5,6]$, these urban low-income groups are still relegated into affordable house in the undesirable locations with limited job accessibility in the long run. 


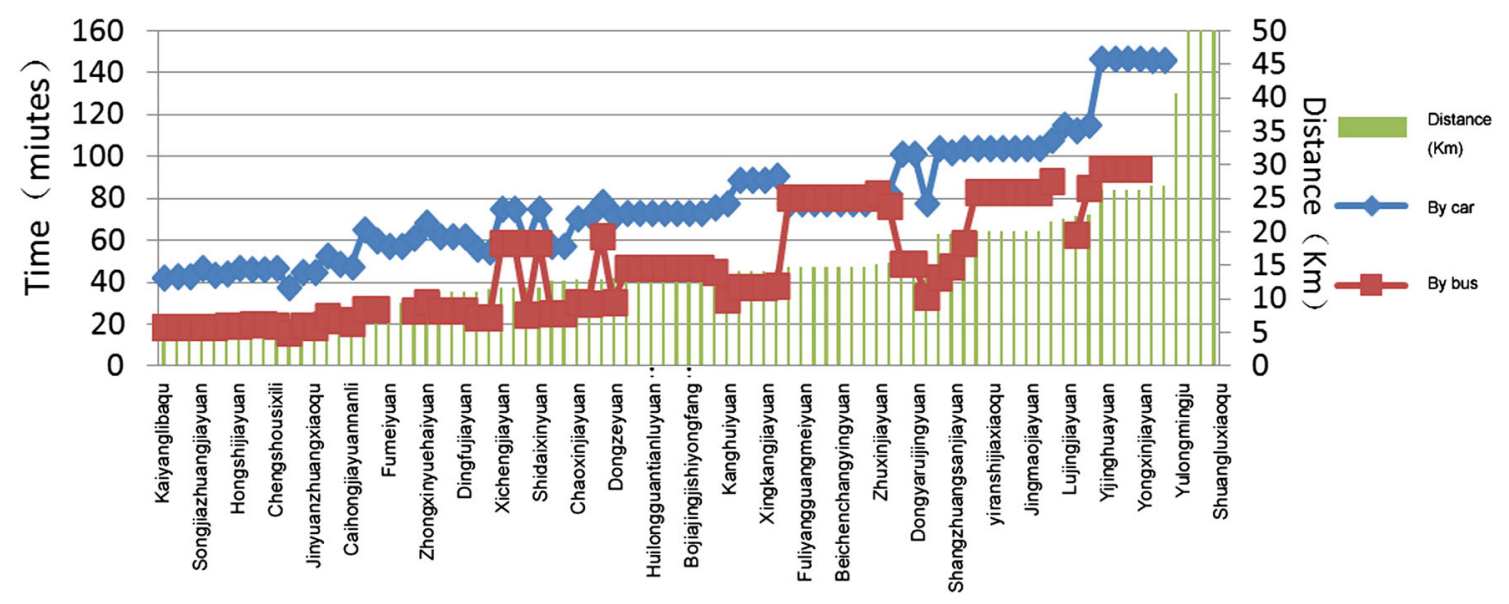

Fig. 9 Distance to city center and commuting time by bus and car for affordable housing (after 2004)

\section{Conclusion}

This paper uses Beijing as case study to explore the job accessibility for low-income groups living in affordable housing areas. A comparison of the average commuting time between using public transit and driving car shows that travel by public transit requires nearly twice the amount of time as driving. This difference in travel methods also reflects the job accessibility gap between different income groups, namely poorer low-income group who take public transit and richer car owners. From the spatial perspective, local public transit is insufficient in areas where travel by both urban metro and bus needs much more time than travel by car. Furthermore, the average commuting time by bus increased from $56.5 \mathrm{~min}$ before 2004 to $74.7 \mathrm{~min}$ after 2004, while the average commuting time by car increases from $28.9 \mathrm{~min}$ before 2004 to $42.8 \mathrm{~min}$ after 2004 . The fact that the residents of new affordable housing areas built after 2004 need to travel longer times after 2004 than before suggests that they are being continuously driven into more disadvantaged locations with limited job accessibility.

Meanwhile, the case study of Beijing shows its unique features of job-housing spatial mismatch as compared to the classical model seen in American cities. In Beijing's case, the affordable housing locations near the city center have better job accessibility, while the locations in the far out suburban areas are weaker in job accessibility. This is different from the classical spatial mismatch hypothesis in which job opportunities move to suburban area, while the low-income groups stay in the inner city [21]. The job opportunities in Chinese cities such as Beijing still concentrated in the inner city without spreading outwards, while the affordable housing areas for low-income groups are being built further and further from the city center. Considering the lack of public transit around these suburban areas, this spatial pattern might induce the low accessibility for low-income groups in Chinese cities.

This unique Chinese model for spatial mismatch reveals the limited accessibility due to income differences. Compared to Western cities, job accessibility in China is based on income factors rather than racial factors $[4,19]$. The limited job accessibility for low-income groups forces them into worse housing locations farther and farther away from job-rich areas. Furthermore, this new spatial mismatch in Chinese cities severs the "spatial bond" which tied housing and employment together within the same Work Unit compound as seen before the economic reform. This broken "spatial bond" also decreases job accessibility for low-income groups.

Exploring job accessibility and its change for low-income individuals can provide implications for future transportation developments and urban land use. For example, in the selection of better locations for future affordable housing projects, urban planners could make sure to make it easier for individuals to access job opportunities, improve local public transit services, or make the last mile home more convenient. Especially for big Chinese cities, establishing well-connected urban rail system for affordable housing residents might be a good way to improve their job accessibility. As the advocators of New Urbanism and Smart Growth proposed, improving the accessibility of low-income groups have many benefits for the entire city, as it will not only reduce private car use and promote urban employment, but also improve social equality for low-income groups. This can then lead planning professionals and decision makers who care about the disadvantaged in the city to provide them with equal footing to employment opportunities.

Acknowledgments Supported by the China Fundamental Research Funds for the Central Universities (2014JBZ020) and the China Ministry of Education Social Science Founding Youth Program (13YJCZH240). 
Open Access This article is distributed under the terms of the Creative Commons Attribution 4.0 International License (http:// creativecommons.org/licenses/by/4.0/), which permits unrestricted use, distribution, and reproduction in any medium, provided you give appropriate credit to the original author(s) and the source, provide a link to the Creative Commons license, and indicate if changes were made.

\section{References}

1. Armstrong M, Sears B (2001) The new economy and jobs/housing balance in Southern California. Retrieved 1 April 2012

2. Beijing Bus (2012) Report on Development of Beijing Bus in Recent Years. Retrieved 3 Dec 2012

3. Beijing Statistical Bureau (2001) Beijing statistical yearbook. China Statistic Press, Beijing

4. Blumenberg E, Ong P (1998) Job accessibility and welfare usage: evidence from Los Angeles. J Policy Anal Manag 17(4):639-657

5. Boustan L, Margob R (2009) Race, segregation, and postal employment: new evidence on spatial mismatch. J Urban Econ 65:1-10

6. Brooks R (2002) Covenants and conventions. Northwestern University School of Law

7. Cervero R (1989) Jobs-housing balance and regional mobility. J Am Plan Assoc 55(2):136-150

8. Cervero R (1991) Jobs/housing balance as public policy. Urban Land 50(10):10-14

9. Cervero R (1996) Jobs-housing balance revisited: trends and impacts in San Francisco Bay area. J Am Plan Assoc 62:492-511

10. Cervero R, Sandoval O et al (2002) Transportation as a stimulus of welfare-to work: private versus public mobility. J Plan Educ Res 22(1):53-63

11. Chai, Y, Zhang, C (2009) Geographical approach to Chinese Cities' Danwei: a key to understand the transition of Urban China. Int Urban Plan 24 (5): 2-6. [柴彦威, 张纯. 地理学视角下的城市单 位:解读中国城市转型的钥匙. 国际城市规划, 2009,24 (5):2-6]

12. Downs A (1992) Stuck in traffic: coping with peak hour traffic congestion. Brookings Institution, Washington, DC

13. Deng FF, Huang Y (2004) Uneven land reform and urban sprawl in China: the case of Beijing. Prog Plan 61:211-236

14. Ellwood D (1986) The spatial mismatch hypothesis: Are there teenage jobs missing in the ghetto? In: Freeman R, Holzer H (eds) The black youth employment crisis. University of Chicago Press, Chicago

15. Ewing R (1996) Best development practices: doing the right thing and making money at the same time. Planners Press, Chicago

16. Grengs J (2010) Job accessibility and the modal mismatch in Detroit. J Transp Geogr 18(1):42-54

17. Handy SL, Niemeier DA (1997) Measuring accessibility: an exploration of issues and alternatives. Environ Plan A 29(7):1175-1194

18. Hansen W (1959) How accessibilitv shapes land use. J Am Inst Plan 25:73-76

19. Holzer H (1991) The spatial mismatch hypothesis: What has the evidence shown? Urban Stud 28(1):105-122

20. Huang, Y. (2005). From work-unit compounds to gated communities: housing inequality and residential segregation in transitional Beijing. Restructuring the Chinese city: changing society, economy and space. L. J. C. M. a. F. L. Wu. London, Routledge

21. Kain J (1968) Housing segregation, negro employment, and metropolitan decentralization. Q J Econ 2:175-197

22. Kain J (1992) The spatial mismatch hypothesis: there decades later. Hous Policy Debate 3(2):371-460

23. Kawabata M (2003) Job access and employment among lowskilled autoless workers in US metropolitan areas. Environ Plan A 35(9):1651-1668

24. Ley D (1993) Social geography of the City. Harper \& Row Press, New York
25. Liu W, Yan X, Xie L (2012) Employment and residential mobility and its spatial structure change based on the 3 years survey analysis. Geogr Res 31(9): 1685-1697. [刘望保,用小培, 谢丽娟.转型时期广州居民职住流动及其空间结构变化一一基 于3个年份的调查分析. 地理研究, 2012, 31(9):s1685-1697]

26. Mattingly D (1999) Job search, social networks, and local labor market dynamics: the case of paid household work in San Diego, California. Urban Geogr 20(1):46-74

27. New Urban News (2010) http://www.newurbannews.com. Retrieved 6 Apr 2010

28. Omer I (2006) Evaluating accessibility using house-level data: a spatial equity perspective. Comput Environ Urban Syst 30:254-274

29. Raphael S (1998) The spatial mismatch hypothesis and black youth joblessness: evidence from the San Francisco Bay Area. J Urban Econ 43:79-111

30. Shen Q (2000) A spatial analysis of job openings and access in a US metropolitan area. J Am Plan Assoc 67(1):53-68

31. Smart Growth America (2007) What is smart growth? Retrieved 13 Dec 2007

32. Taylor B, Ong P (1955) Spatial mismatch or automobile mismatch? An examination of race, residence, and commuting in US metropolitan areas. Urban Stud 32(9):1537-1557

33. Wachs M, Kumagai TG (1973) Physical accessibility as a social indicator. Soc Econ Plan Sci 7:437-456

34. Wang E, Song J, Xu T (2011) From "spatial bond" to "spatial mismatch": an assessment of changing jobs housing relationship in Beijing. Habitat Int 35:398-409

35. Warner SBJ (1978) Streetcar suburbs: The process of growth in Boston 1870-1990. Harvard University Press, Cambridge

36. Weitz J, Schindler T. (1997) Are Oregon's communities balanced? A test of the jobs-housing balance policy and the impact of balance on mean commute times. Unpublished manuscript. Department of Urban Studies and Planning, Portland State University

37. Zhang C, Chai Y (2014) Un-gated and integrated work unit communities in post-socialist urban China: a case study from Beijing. Habitat Int 43:79-89

38. Zhao P, Lu B (2010) Exploring job accessibility in the transformation context: an institutionalist approach and its application in Beijing. J Transp Geogr 18:393-401

39. Zhao P, Lu B et al (2009) Consequences of governance restructuring for quality of urban living in the transformation era in Beijing: a view of job accessibility. Habitat Int 33:436-444

40. Liu B, Shen F (2008) Study on the characters of job-housing spatial structure in Beijing metropolitan area. Hum Geogr 120 (4):40-47 (In Chinese) [刘碧寒, 沈凡卜. 北京都市区就业一居 住空间结构及特征研究. 人文地理, 2008, 120(4):40-47]

41. Liu Z, Wang M (2011) The influence of job-housing mismatch on commuting behavior of residents in Beijing: based on the anaylsis of accessibility and commuting time. Acta Geogr Sin 65:191. [刘] 志林，王茂军.北京市职住空间错位对居民通勤行为的影响分 析一一基于就业可达性与通勤时间的讨论. 地理学报，2011, 66(4):457-467]

42. Sun F, Wang Z (2003) Statistical analysis of the average speed of buses in Beijing. Automot Eng 25(3):219-242. [孙逢春, 王震坡 等. 北京市公共汽车平均车速统计分析. 汽车工程, 2003, 25 (3):219-242]

43. Zhou J, Zhang C, Chen XJ, Huang W, Yu P (2014) Has the legacy of Danwei persisted in transformations? the jobs-housing balance and commuting efficiency in Xi' an. J Transp Geogr 40:64-76

44. Lu B, Zhang C, Chen TM (2013) Study on changes in job accessibility for the urban low-income: a case study of Beijing. City Plan Rev 37(1):56-63. [吕斌, 张纯, 陈天鸣. 城市低收入群 体的就业可达性变化研究一以北京为例. 城市规划, 2013, 37 (1):56-63] 